\title{
STUDY OF SOLID MODERATORS FOR THE THERMAL-SPECTRUM SUPERCRITICAL WATER-COOLED REACTOR (THERMO- MECHANICS AND COST)
}

\author{
Jacopo Buongiorno \\ Idaho National Engineering and \\ Environmental Laboratory (INEEL) \\ P.O. Box 1625, Idaho Falls, ID 83415 \\ Phone: (208)526-3440, Fax: 526-2930 \\ E-mail: buoni@inel.gov
}

\author{
Philip E. MacDonald \\ Idaho National Engineering and \\ Environmental Laboratory (INEEL) \\ P.O. Box 1625, Idaho Falls, ID 83415 \\ Phone: (208)526-9634, Fax: 526-2930 \\ E-mail: pem@inel.gov
}

The feasibility of zirconium hydride as the moderator of a thermal-spectrum supercriticalwater cooled nuclear reactor (SCWR) was assessed. Several issues were evaluated including zirconium-hydride / water interaction, hydrogen release, hydrogen redistribution, pressurization of the moderator box at high temperature, phase stability, and compatibility of zirconium hydride with the moderator box material. It was found that:

- The chemical reaction of zirconium hydride with water is thermodynamically favored but kinetically impaired even at high temperatures.

- Hydrogen release is low at steady-state, while the use of a hydrogen-impermeable coating on the inner surface of the moderator box might be required at higher temperatures.

- The moderator-box wall temperature during a LOCA should be limited to $900^{\circ} \mathrm{C}$ to prevent failure from internal hydrogen pressure.

- Hydrogen redistribution and release do not threaten the stability of $\delta$-phase zirconium hydride.

- The use of a solid moderator greatly enhances the thermal capacity of the SCWR core.

- The issues of hydriding and hydrogen embrittlement of the moderator box material, Alloy 718 , appear of little concern, while high-temperature diffusion of zirconium into Alloy 718 might have to be prevented by means of a thin molybdenum protective coating.

Finally, fabrication of the SCWR moderator rods appears feasible within the envelope of existing technology. Also, a simple analysis indicated that the use of zirconium-hydride moderator will not result in a significant economic penalty for the SCWR.

Several issues key to the neutronic feasibility of zirconium hydride were also assessed and are discussed in a separate paper (\# 36571) presented at this conference. At this point no insurmountable difficulties have been identified in the development of zirconium hydride moderator rods for SCWR thermal-spectrum cores. 